\title{
Neuropsychological symptoms in Chinese male and female painters: an epidemiological study in dockyard workers
}

\author{
Ruoling Chen, Li Wei, Anthony Seaton
}

\begin{abstract}
Objectives-To study the prevalences of neuropsychological symptoms in male and female dockyard painters in China and to compare them with those in British dockyard painters.

Methods-All 116 painters were identified, active and retired, who had been employed in two Chinese dockyards for at least 1 year together with a matched random sample of 263 dockyard nonpainters. Neuropsychological and personality questionnaires that we had used previously in a study of United Kingdom dockyard painters were used, translated into Chinese. Neuropsychological symptoms in painters and controls were compared, adjusting for age, educational level, smoking, alcohol intake, and personality. Results-The response rate was $94 \%$ for painters and $\mathbf{9 7 \%}$ for controls. Highly significant excesses of symptoms were found in painters, suggestive of neuropsychological dysfunction. Both male and female painters showed higher relative risks than were found in similar tradespeople in the United Kingdom. The relative risk increased with increasing score of both neurological and psychological symptoms. Relative risk of having a high symptom score, compared with controls and adjusted for confounders, was $6.61(95 \%$ confidence interval (95\% CI) 2.36 to 18.50 ) for 2-15 years exposure, 14.88 (5.74 to 38.56) for 16-22 years and 9.42 (3.97 to 22.36) for $\geqslant 22$ years.

Conclusion-These results indicate that neuropsychological symptoms are associated with heavy exposure to painting work in China, and that the phenomenon is likely to be found worldwide wherever there is such exposure to solvent based paints. The high response rate in this study answers a possible criticism of the earlier United Kingdom study.

(Occup Environ Med 1999;56:388-390)
\end{abstract}

Keywords: neuropsychology; painters; dockyards

In the 1970 s and 1980 s several reports were published from the Nordic countries both of solvent exposed patients with symptoms suggestive of a psycho-organic or neurasthenic syndrome, and of epidemiological studies indicating an association of chronic neurotoxic effects with long term occupational exposure to organic solvents. ${ }^{1}$ The typical symptoms re- ported were memory disturbances, excessive tiredness, personality changes (including depression), irritability, intellectual reduction, and problems in maintaining a job and other social functions. Nevertheless, some scepticism has been expressed that such effects occur commonly nowadays. More recently one of the authors reported severe neurological disease in British dockyard painters heavily exposed to solvents, ${ }^{2}$ and in a subsequent epidemiological investigation we have shown relations between painting exposure in this workforce and symptoms of neuropsychological dysfunction. ${ }^{3}$ Most recent studies of this problem have been from developed countries where controls of occupational exposure might have been expected to be relatively tight. They have also been made almost exclusively in men. We have carried out a study in Chinese dockyard painters, with the same methods as in our investigation of United Kingdom dockyard painters, ${ }^{3}$ to investigate further the neuropsychological effects of paint exposure in both sexes.

\section{Subjects and methods}

Two dockyards were identified in Anhui, China. They were built in the 1950s and are located along the Yangzhi river. It was estimated that workplace exposure environments were similar to those in the dockyard that we studied in Scotland. ${ }^{2}$ We obtained the approval of the dockyard administrators for this study. From the paintshops, and with personnel and pension department records, we selected the 116 active and retired painters who had worked for at least 1 year (50 women, 66 men) as subjects. As controls, 263 non-painters (75 women, 188 men) who had not been exposed to organic solvents were randomly selected. Current workers were sampled from two workshops of labourers while retired subjects (about $10 \%$ of those identified) were sampled from personnel records kept by the pension department (matched by sex and age to within 5 years).

The investigation was carried out with the questionnaire which had been used in our United Kingdom study. ${ }^{3}$ It includes personal, smoking, alcohol, and occupational histories, neuropsychological symptoms, and a personality inventory. We translated the English version into Chinese and tested it for comprehensibility on Chinese doctors in Anhui Medical University and workers in the dockyards. The questionnaires and invitations to participate were delivered to the subjects, all of whom were asked to complete them; current employees did 
Table 1 Relative risks of neuropsychological symptoms among dockyard painters and controls

\begin{tabular}{|c|c|c|c|c|}
\hline \multirow[b]{2}{*}{ No } & \multirow[b]{2}{*}{ Questions and symptoms } & \multicolumn{2}{|l|}{ China } & \multirow{2}{*}{$\begin{array}{l}U K^{\star} \text { Men } R R \\
(95 \% C I)\end{array}$} \\
\hline & & Women RR $(95 \%$ CI) & Men RR $(95 \% C I)$ & \\
\hline 1 & Do you have a short memory? & $2.15(1.55$ to 2.97$)$ & $1.82(1.51$ to 2.19$)$ & $1.42(1.15$ to 1.73$)$ \\
\hline 2 & Have you ever been told that you have a short memory? & $1.97(1.42$ to 2.72$)$ & $1.71(1.36$ to 2.16$)$ & $1.27(1.01$ to 1.58$)$ \\
\hline 3 & Do you often have to make notes about what you must remember? & $1.50(1.04$ to 2.17$)$ & $1.77(1.40$ to 2.21$)$ & $0.88(0.73$ to 1.06$)$ \\
\hline 4 & $\begin{array}{l}\text { Do you often have to go back to check things that you have done, such as turned } \\
\text { off the stove, locked the door, etc? }\end{array}$ & $1.69(1.13$ to 2.54$)$ & $1.40(1.08$ to 1.81$)$ & $1.27(1.09$ to 1.47$)$ \\
\hline 5 & $\begin{array}{l}\text { Do you generally find it hard to get the meaning from reading the newspaper and } \\
\text { books? }\end{array}$ & $1.53(0.91$ to 2.54$)$ & 2.35 (1.66 to 3.33$)$ & $1.55(1.03$ to 2.34$)$ \\
\hline 6 & Do you often have problems with concentrating? & $2.66(1.70$ to 4.14$)$ & $2.53(1.85$ to 3.47$)$ & $1.41(1.13$ to 1.77$)$ \\
\hline 7 & Do you often feel irritated without any particular reason? & $2.41(1.43$ to 4.09$)$ & $2.62(1.86$ to 3.69$)$ & $1.20(0.98$ to 1.47$)$ \\
\hline 8 & Do you often feel depressed for no particular reason? & $3.06(1.51$ to 6.19$)$ & $2.94(1.82$ to 4.75$)$ & $1.38(1.08$ to 1.77$)$ \\
\hline 9 & Are you abnormally tired? & $2.99(1.82$ to 4.92$)$ & $2.66(1.85$ to 3.83$)$ & 1.51 ( 1.16 to 1.97$)$ \\
\hline 10 & Are you less interested in sex than you think is normal? & $1.66(0.89$ to 3.07$)$ & $1.37(0.77$ to 2.47$)$ & $1.33(1.03$ to 1.72$)$ \\
\hline 11 & Do you have palpitations of the heart even when you don't exert yourself? & $2.52(1.63$ to 3.87$)$ & $2.47(1.73$ to 3.52$)$ & $1.52(1.10$ to 2.11$)$ \\
\hline 12 & Do you sometimes feel a pressure in your chest? & $3.10(1.85$ to 5.22$)$ & $2.17(1.49$ to 3.16$)$ & $1.47(1.16$ to 1.85$)$ \\
\hline 13 & Do you perspire without any particular reason? & $2.41(1.15$ to 5.07$)$ & $2.58(1.42$ to 4.70$)$ & $1.62(1.23$ to 2.13$)$ \\
\hline 14 & Do you have a headache at least once a week? & $2.46(1.64$ to 3.73$)$ & $3.18(2.07$ to 4.88$)$ & $1.36(1.06$ to 1.74$)$ \\
\hline 15 & Do you often have a painful tingling in some part of your body? & $2.66(1.46$ to 4.85$)$ & $1.87(1.20$ to 2.92$)$ & $1.69(1.33$ to 2.15$)$ \\
\hline 16 & Do you have any problems buttoning and unbuttoning? & $10.14(1.29$ to 79.9$)$ & $4.22(1.78$ to 9.99$)$ & $2.93(1.73$ to 4.96$)$ \\
\hline 17 & Do you have bouts of dizziness? & $1.99(1.36$ to 2.91$)$ & $2.21(1.47$ to 3.34$)$ & $1.84(1.31$ to 2.58$)$ \\
\hline 18 & Do your hands tremble? & $4.64(1.82$ to 11.80$)$ & $3.68(2.19$ to 6.17$)$ & $2.21(1.53$ to 3.20$)$ \\
\hline 19 & Do you bump into people or things when moving around? & $1.74(0.56$ to 5.38$)$ & 8.69 (3.59 to 21.00$)$ & $1.73(1.04$ to 2.89$)$ \\
\hline 20 & Do you feel weak or unsteady in your arms or legs? & $3.70(1.88$ to 7.30$)$ & $2.50(1.54$ to 4.04$)$ & $2.11(1.54$ to 2.90$)$ \\
\hline 21 & $\begin{array}{l}\text { Do you find that you can't quite remember things although they are on the tip of } \\
\text { your tongue? }\end{array}$ & $1.85(1.27$ to 2.70$)$ & $1.39(1.05$ to 1.84$)$ & $1.10(0.96$ to 1.25$)$ \\
\hline 22 & Do you have difficulty falling asleep? & $2.09(0.97$ to 4.51$)$ & 2.59 (1.85 to 4.70$)$ & $1.56(1.25$ to 1.94$)$ \\
\hline
\end{tabular}

$\star$ See reference ${ }^{3}$.

this individually in the workshops, whereas retired workers completed the questionnaires at the pension department or at home. We collected the questionnaires personally.

Data analysis was similar to that of the United Kingdom study. ${ }^{3}$ In brief, we calculated prevalence rate ratios or relative risk (RR) in turn for each symptom and then for the summary scores of neuropsychological symptoms. The questions are shown in table 1; questions 1-16 are summarised as asking about psychological symptoms, and questions 15-22 neurological. With the Breslow-Cox model,${ }^{4}$ these analyses were adjusted for age, sex (where necessary), educational level, smoking, alcohol intake, and social conformity scores. The relation between symptom scores and years of painting was examined. A logistical regression model was also used in a multivariate analysis for subjects with higher scores versus those with lower scores to investigate effects of exposure to paint and other possible confounding factors.

\section{Results}

Questionnaires were completed by 109 painters (49 women, 60 men) and 255 non-painters (71 women, $184 \mathrm{men}$ ), giving response rates of

Table 2 Relative risk of psychological symptoms (Q1-16, table 1) in painters $v$ controls by $\operatorname{sex}$

\begin{tabular}{llllllll}
\hline \multirow{2}{*}{$\begin{array}{l}\text { Symptom } \\
\text { scores }\end{array}$} & \multicolumn{2}{l}{ Subjects $(n)$} & & & & \\
\cline { 2 - 3 } & Controls & Painters & Total & $R R$ & $95 \% C I$ & $R R^{*}$ & $95 \% C I^{*}$ \\
\hline Women: & & & & & & & \\
$0-3$ & 40 & 7 & 47 & 0.25 & 0.12 to 0.52 & 0.31 & 0.13 to 0.75 \\
$4-6$ & 14 & 10 & 24 & 1.03 & 0.50 to 2.14 & 0.85 & 0.31 to 2.38 \\
$7-9$ & 11 & 10 & 21 & 1.32 & 0.61 to 2.86 & 1.36 & 0.51 to 3.61 \\
$10-16$ & 6 & 22 & 28 & 5.31 & 2.33 to 12.1 & 4.60 & 1.69 to 12.5 \\
Total & 71 & 49 & 120 & & & & \\
Men: & & & & & & & \\
$0-3$ & 95 & 11 & 106 & 0.36 & 0.20 to 0.62 & 0.28 & 0.15 to 0.53 \\
$4-6$ & 42 & 14 & 56 & 1.02 & 0.60 to 1.74 & 1.41 & 0.75 to 2.66 \\
$7-9$ & 30 & 10 & 40 & 1.02 & 0.53 to 1.97 & 1.17 & 0.56 to 2.46 \\
$10-16$ & 17 & 25 & 42 & 4.51 & 2.62 to 7.76 & 5.29 & 2.79 to 10.0 \\
Total & 184 & 60 & 244 & & & & \\
\hline
\end{tabular}

^Adjustment for age, educational level, smoking, alcohol intake, and social conformity.
$94 \%$ for painters and $97 \%$ for non-painters. There was a significant excess of symptoms overall among painters over non-painters of both sexes. The highest relative risks (RRs) of symptoms for women were from having problems with buttoning and unbuttoning (10.14, 95\% confidence interval (95\% CI) 1.29 to 79.90$)$ and hands trembling (4.64, 1.82 to 11.8 ), and for men were from bumping into people or things when moving around (8.69, 3.59 to 21.0 ) and having problems with buttoning and unbuttoning $(4.22,1.78$ to 9.99). Further detail is shown in table 1 . Higher RRs were found in Chinese painters than had previously been shown in our study of United Kingdom painters (table 1). Summarised scores further show that the painters had more neuropsychological symptoms than had the controls (tables 2 and 3), the RRs being increased with increasing scores of both psychological symptoms and neurological symptoms (trend test $\mathrm{p}<0.001$ ), and these persisted even in the adjusted analysis. A combination of all neuropsychological symptoms in both sexes showed a similar pattern: RR was $0.44(0.32$ to 0.60$)$ for subjects with a symptom score of $0-6,1.33$ (1.00 to 1.76 ) for a score of 7-14 and 7.49 (3.82 to 14.7) for a score of 15-22. After adjustment for sex, age, educational level, smoking, alcohol intake, and social conformity, the RRs were 0.41 ( 0.27 to 0.61 ), 1.49 (1.01 to 2.19) and 9.64 (4.55 to 20.4) respectively. Based on these symptom scores, we found a relation $\left(\chi^{2} 58.2, \mathrm{p}<0.0001\right)$ between duration of solvent exposure and scores of $\geqslant 15$ (table 4 ), but in the adjusted analysis the highest risk was with an exposure of 16-21 years and the trend was not significant. The multivariate analysis of 77 cases with a score $\geqslant 12$ and 158 controls with a score $\leqslant 4$ showed an odds ratio (OR) of 24.8 (95\% CI 6.0 to 103 ) for $\leqslant 15$ years' exposure to painting increasing to 32.0 (8.9 to 115 ) for $16-43$ years. Non-significant increases in ORs 
Table 3 Relative risk of neurological symptoms (Q15-22, table 1) in painters $v$ controls by $\operatorname{sex}$

\begin{tabular}{|c|c|c|c|c|c|c|c|}
\hline \multirow{2}{*}{$\begin{array}{l}\text { Symptom } \\
\text { scores }\end{array}$} & \multicolumn{3}{|c|}{ Subjects (n) } & \multirow[b]{2}{*}{$R R$} & \multirow[b]{2}{*}{$95 \% C I$} & \multirow[b]{2}{*}{$R R^{\star}$} & \multirow[b]{2}{*}{$95 \% C I^{\star}$} \\
\hline & Controls & Painters & Total & & & & \\
\hline \multicolumn{8}{|l|}{ Women: } \\
\hline 0 & 35 & 6 & 41 & 0.25 & 0.11 to 0.55 & 0.26 & 0.10 to 0.66 \\
\hline 1 & 12 & 7 & 19 & 0.85 & 0.36 to 1.99 & 1.29 & 0.44 to 3.81 \\
\hline 2 & 10 & 9 & 19 & 1.30 & 0.57 to 2.97 & 0.66 & 0.23 to 1.95 \\
\hline $3-4$ & 10 & 14 & 24 & 2.03 & 0.98 to 4.19 & 2.55 & 0.97 to 6.76 \\
\hline $5-8$ & 4 & 13 & 17 & 4.71 & 1.63 to 13.6 & 4.05 & 1.16 to 14.2 \\
\hline Total & 71 & 49 & 120 & & & & \\
\hline \multicolumn{8}{|l|}{ Men: } \\
\hline 0 & 78 & 13 & 91 & 0.51 & 0.31 to 0.85 & 0.45 & 0.25 to 0.82 \\
\hline 1 & 47 & 13 & 60 & 0.85 & 0.49 to 1.46 & 0.79 & 0.41 to 1.49 \\
\hline 2 & 27 & 6 & 33 & 0.68 & 0.30 to 1.57 & 0.85 & 0.34 to 2.11 \\
\hline $3-4$ & 21 & 11 & 32 & 1.61 & 0.82 to 3.14 & 1.91 & 0.89 to 4.11 \\
\hline $5-8$ & 11 & 17 & 28 & 4.74 & 2.53 to 9.55 & 5.91 & 2.67 to 13.1 \\
\hline Total & 184 & 60 & 244 & & & & \\
\hline
\end{tabular}

^Adjustment for age, educational level, smoking, alcohol intake, and social conformity.

Table 4 Relative risks of all neuropsychological symptoms (Q1-22, table 1) by years of painting exposure

\begin{tabular}{|c|c|c|c|c|c|c|}
\hline \multirow[b]{3}{*}{ Scores } & \multicolumn{6}{|c|}{ Duration of exposure (y) } \\
\hline & \multicolumn{2}{|l|}{$2-15$} & \multicolumn{2}{|l|}{$16-21$} & \multicolumn{2}{|l|}{$22-43$} \\
\hline & $R R$ & $95 \% C I$ & $R R$ & $95 \% C I$ & $R R$ & $95 \% C I$ \\
\hline \multicolumn{7}{|c|}{ Unadjusted: } \\
\hline $0-6$ & 0.59 & 0.40 to 0.88 & 0.25 & 0.12 to 0.53 & 0.47 & 0.27 to 0.81 \\
\hline $7-14$ & 0.42 & 0.98 to 2.08 & 1.53 & 1.05 to 2.23 & 0.94 & 0.53 to 1.68 \\
\hline $15-22$ & 4.25 & 1.71 to 10.5 & 8.96 & 4.24 to 18.9 & 10.20 & 4.82 to 21.6 \\
\hline \multicolumn{7}{|c|}{ Adjusted ${ }^{\star}$ : } \\
\hline $0-6$ & 0.49 & 0.29 to 0.83 & 0.22 & 0.10 to 0.51 & 0.52 & 0.26 to 1.03 \\
\hline $7-14$ & 1.90 & 1.12 to 3.24 & 2.07 & 1.18 to 3.63 & 0.82 & 0.41 to 1.64 \\
\hline $15-22$ & 6.61 & 2.36 to 18.5 & 14.88 & 5.74 to 38.6 & 9.42 & 3.97 to 22.4 \\
\hline
\end{tabular}

^Adjusted for age, sex, educational level, smoking, alcohol intake, and social conformity.

were found for women who had high scores compared with men (1.61, 0.57 to 4.56$)$, for smoking $\geqslant 20 v 0$ cigarettes $(2.70,0.77$ to 9.53$)$ and for ageing (60-82 v 18-29 years old$4.85,0.88$ to 26.7$)$. The ORs showed no associations with educational level and alcohol intake.

\section{Discussion}

This study complements our United Kingdom study of dockyard painters, in which we reported significant differences between painters and community controls for neuropsychological symptoms, and to which we refer the reader for a discussion of the relevant publications. ${ }^{3}$ Although the numbers of subjects were smaller in the present study, the similarities in the results give strong support to our finding that neuropsychological ill health may be associated with common occupational exposures to organic solvents. The present study has the strength derived from a higher response rate than we had in our United Kingdom study, and thus suggests that bias was not responsible for our earlier findings. Also, we have taken the opportunity of examining the neuropsychological effects of exposure to paint solvents in women, as in China women make an important contribution to the manual workforce; it was not surprising to find similar effects.

Although we included all painters recorded as having been employed in the dockyards, it is possible that some (mainly older subjects) may have been excluded owing to earlier retirement on grounds of illness or having left the dockyards a long time ago, because of incomplete records. Moreover, we were unable to include many short term workers for whom the dockyard held no records. The retired workers could have led to an underestimate of the effect. Nevertheless, the RRs in this investigation were higher than in our United Kingdom study, suggesting either that the exposures have been higher in China or that the population is more susceptible. Our findings suggest that exposures in both countries have been very high and often in confined spaces, but we have no direct measurements in the Chinese dockyards. Genetic differences between Chinese and Scottish populations remain a possible explanation. There may (for example) be differences in expression of genes for glutathione-S-transferase and n-acetyltransferase enzymes between populations which could make some more susceptible to the effects of xenobiotic substances than others. ${ }^{5}$ It also remains possible that the lower response rate in the United Kingdom study introduced a bias that caused us to underestimate the effects there.

This study also has shown an indication of an exposure-response relation, although this was not as clear cut as in the United Kingdom study where we had many more subjects. In the adjusted analysis we found that the highest risks was associated with intermediate durations of exposure, with a fall in risk among those exposed for very long periods. This may simply have been due to small numbers or may be a survival effect, reflecting the possibility that those who persist longest in the trade are those who are most resistant to the effects of solvents.

This study reinforces our earlier warnings of the dangers of uncontrolled exposures to organic solvents in industry. ${ }^{6}$ Excessive exposure may lead to both neurological and psychological morbidity, manifesting as nonspecific ill health unrecognised by most doctors and thus often undiagnosed. Our current research seeks to clarify these issues further.

This study was funded by a research grant from The Royal Society. We thank Anhui Medical University and Dockyards for their great help in data collection. We are also grateful to the Colt Foundation for its initial grant to RC.

1 Hogstedt C. Has the Scandinavian solvent syndrome controversy been solved? Scand $\mathcal{f}$ Work Envrion Health 1994;20(suppl):59-64

2 Seaton A, Jellinek EH, Kennedy P. Major neurological diseases and occupational exposure to organic solvents. $Q \mathcal{F}$ Med 1992;305:707-12.

3 Chen R, Dick F, Seaton A. Health effects of solvent exposure among dockyard painters; mortality and neuropsychological symptoms. Occup Environ Med 1999;56:3837 .

4 Lee J. Odds ratio or relative risk for cross sectional data? Int f Epidemiol 1994;23:201-3.

5 Soderkvist P, Ahmadi A, Akerback A, et al. Glutathione S-transferase null genotype as a risk modifier for solventinduced chronic toxic encephalopathy. Scand $\mathcal{F}$ Work Environ Health 1996;22:360-3.

6 Seaton A. Organic solvents and the nervous system: time for a reappraisal? [Editorial]. $Q \mathcal{F} \mathrm{Med}$ 1992;305:637-9. 